\title{
Percutaneous injection of Acetic Acid and Mitoxantrone Versus Radiofrequency Ablation in Treatment of Hepatocellular Carcinoma
}

\author{
Emad A Moustafa ${ }^{1}$, Ibrahim M Hegazy ${ }^{1}$, Rashed M Hassan ${ }^{1}$, \\ Nashwa E Nawar ${ }^{2}$, Mostafa H El-Shamy ${ }^{1}$, Soha A Elhawari ${ }^{1}$ \\ ${ }^{I}$ Tropical Medicine Department, Faculty of Medicine, Zagazig University, Egypt. \\ ${ }^{2}$ Clinical Oncology and Nuclear Medicine Department, Faculty of Medicine, Zagazig University, Egypt
}

Corresponding Author Emad A Moustafa

Mobile:

$+01003725577$

E mail:dr.emad777@yah oo.com

Key words: Hepatocellular carcinoma, mitoxantrone radiofrequency ablation
Background and study aim: Hepatocellular carcinoma (HCC) is currently the fifth most common solid tumor worldwide and the third leading cause of cancer-related death. New therapeutic choices have been developed for HCC, including percutaneous ablation therapy, transarterial chemoembolization and molecular target therapy. Percutaneous acetic acid injection (PAI) and radiofrequency ablation (RFA) techniques became well-known procedures for controlling small HCC.The aim of this study was to compare the outcomes of per-cutaneous combined PAI and mitoxantrone injection versus RFA in the treatment of HCC.

Patients and Methods: This prospective study was conducted on 120 patients with 120 focal nodular HCCs of $4 \mathrm{~cm}$ or less between 2012 and 2014. They were randomly divided into 2 groups, the first group included 60 patients treated with PAI plus percutaneous intratumoral injection of mitoxantrone, and the second group included 60 patients treated with radiofrequency ablation. Clinical assessment, laboratory evaluation and triphasic CT studies were performed to all patients pretreatment and at 1,3,6 and 12 months post treatment and complications were recorded. Results: The percentage of ablation in both groups at 1, 3, 6 and 12 months were $85 \%, 83.33 \%, 78.34$ and $73.33 \%$ in group I versus $88.33 \%, 88.3 \%, 85 \%$ and $81.66 \%$ in group II respectively with no statistical significant difference between the two groups. Percentage of ablation in small tumors was higher than large tumors in both groups. Side effects and complications are statistically higher in group II than group I. Conclusion: Combination of PAI and Mitoxantrone is comparable to radiofrequency ablation in treatments of HCCs with less frequent complications.

ablation (RFA), and surgical resection or liver transplantation. These treatments provide better survival rates at 5-years of $40-70 \%$ vs $<20 \%$ for untreated patients; however, they are applicable in only $30-40 \%$ of patients with HCC $[5,6]$.

Percutaneous ablation under ultrasound guidance is currently the best therapy for early-stage HCC when resection or liver transplantation is not possible [7]. RFA is currently considered the most effective local ablative therapy [8]. It causes coagulative necrosis of the liver tumor by using electric heating around a probe generating electromagnetic radiation [9]. 
Acetic acid used as a 50\% solution is as cheap as alcohol and in contrast penetrates and destroys intra-nodule septa because of its low $\mathrm{pH}[\mathbf{1 0}]$ and breaks down lipid and collagen fibres within intra-tumoural septa and capsules which often contain cancer cells. PAI is performed as easily and safely as PEI but requires fewer treatment sessions [11].

Mitoxantrone is a cycle specific anthracyclin which induces persistent intracellular DNA damage. It is used as an anticancer agent and has demonstrated clinical activity when administered via multiple routes: intravenous, intraperitoneal, intrapleural, intrapericardial, or intrathecal [12]. Mitoxantrone was selected for palliative local treatment of malignant liver lesions because of its low tissue toxicity, high intratumoral concentration after intratumoral instillation, since it has a tendency to remain at the application site [13, 14]. In 1998, Farrés et al. [15] concluded that in patient with malignant liver lesions, minimally invasive intratumoral mitoxantrone injection was carried out safely with good tumor delivery of chemotherapy, and tumor necrosis was demonstrated at biopsy, but they advised further investigations .

The aim of this study was to assess the efficacy and safety of combined PAI and intralesional mitoxantrone versus radiofrequency ablation in treatment of HCC.

\section{PATIENTS AND METHODS}

This prospective study was conducted in Tropical Medicine Department in cooperation with Clinical Oncology \& Nuclear Medicine Department Faculty of Medicine, Zagazig University, Egypt, during the period from March 2012 to September 2014 and included 120 patients presented with 120 focal hepatocellular carcinoma lesions. Sample size estimation was performed by the Institutional Review Board (IRB). The lesions were randomly divided into 2 groups.

Group I: (acetic acid and mitoxantrone group) consisted of 60 patients (46 males and 14 females) treated by percutaneous acetic acid injection therapy (PAI) performed at multiple sessions according to the volume estimated, followed by intralesional single injection with mitoxantrone.

Group II: (radiofrequency ablation group) consisted of 60 patients (51 males and 9 females) treated by percutaneous RFA.

The diagnosis of HCC in a patient with hepatic focal lesion was based on triphasic CT-scan showing typical criteria for HCC (early enhancement during arterial phase followed by washout of contrast in porto-venous and delayed phases) or by liver biopsy.

All patients met the enrolment criteria: (i) tumor of $4 \mathrm{~cm}$ or less in diameter, (ii) liver cirrhosis classified as Child-Pugh class A or B, (iii) platelet counts $>50000 \mathrm{~mm}^{3}$, (iv) prothrombin concentration $>60 \%$ or INR $<1.5$, (v) no evident ascites and (vi) Performance status 0-2.

Patients with a Child-Pugh class $\mathrm{C}$, previous history of treatment for HCC, vascular invasion, lymph node or distant metastasis were excluded.

\section{Pretreatment assessment}

Pre-treatment assessment of all patients was done by full history taking, thorough clinical examination, laboratory investigations including $\mathrm{CBC}$, liver function, kidney function, $\alpha$ fetoprotein, and serological markers for $\mathrm{HCV}$ and HBV. Radiological examination including ultrasound, triphasic CT study, and ultrasound guided biopsy when indicated.

\section{Technique of Acetic Acid Ablation}

Treatment was performed with the patient under conscious sedation. Injection of acetic acid was performed under real-time US guidance (esaote MyLab20Plus) using a $3.5 \mathrm{MHz}$ probe by free hand technique. Sterile 50\% acetic acid was injected with a 18 -gauge spinal needle.

Typically, one injection at a dose of 5-10 ml acetic acid was given during each treatment session. Acetic acid was slowly injected until the echogenic area appearing immediately after injection covered the entire tumor. After the injection was completed, the needle was left in place for 1-2 $\mathrm{min}$ then injection of local anesthetic during withdrawal to minimize the irritant effect of acetic acid reflux on the liver capsule [16].

$50 \%$ acetic acid was injected at a volume of $1-10$ $\mathrm{mL}$ per session and total volume was estimated using the modified equation: $V=1 / 3\{4 / 3 \pi(r+$ $\left.0.5)^{3}\right\}$ where $V$ is the total volume of acetic acid in milliliters $(\mathrm{mL})$ and $r$ is the radius of each tumor in centimeters $(\mathrm{cm})$ and $0.5 \mathrm{~cm}$ is added to provide a safety margin of ablation [10].

Four to six sessions were given for lesions. There was no need to give prophylactic antibiotics. Treatment was administered once a week in an outpatient setting. 


\section{Mitoxantrone injection:}

This was done to patients of group I after complete sessions of acetic acid. Ultrasound guided injection of mitoxantrone mixed with lipidol at the time of injection in a single session; the dose of mitoxantrone is $0.5 \mathrm{mg}$ per cubic centimeter of the tumor size. Re-evaluation of the patients was done by laboratory investigations, ultrasound and triphasic CT after treatment and every 3 moths up to one year.

\section{Technique of RFA :}

The technique was the same with the addition of a small opening is done into the skin using a scalpel (No 11). We used a common, commercially available RFA technique and system (RITA 1500X RF generator and RITA StarBurst XL, RITA Medical Systems, Mountain View, California). Grounding was achieved by attaching 2 pads to the patient's thighs. After administration of analgesia as well as local anesthesia, the electrode needles were introduced into the tumor under ultrasonographic guidance, then a gradual unfolding of the electrodes was obtained, and the generator was activated to achieve RF energy and maintain an average temperature of $105^{\circ} \mathrm{C}$. At first, the electrodes were moved by $2 \mathrm{~cm}$, then the electrode needles were pushed forward and unfolded gradually to $3 \mathrm{~cm}, 4 \mathrm{~cm}$ and $5 \mathrm{~cm}$ until they reached or crossed the borders of the tumor according to the ablation range, delivering RF energy for 5 minutes for every intermediate step and for 7 to 10 minutes in the final step of the procedure. The ablation area was intended to cover the tumor as well as at least 0.5 to $1.0 \mathrm{~cm}$ of the surrounding tissue [17].

Following therapy, patients were put under observation for 6 hours where vital signs were checked every half-hour.

\section{Assessment of therapeutic response and follow-up}

Included all the investigations that were done before procedure. AFP and triphasic spiral CT were done after one month and every three months up to one year. The response to treatment was rated as complete when dynamic CT scans showed no contrast enhancement inside the lesion in the arterial phase. The response was rated as partial when dynamic CT showed areas of enhancement within the boundaries of the original lesion in the arterial phase [18].

Follow up of the patients of the two groups was done for one year with special emphasis on recurrence of $\mathrm{HCC}$, any remote complications related to both procedure, development of liver decompansation (ascites, jaundice, encephalopathy, bleeding tendency), haematemesis, or death.

\section{Statistical Analysis :}

Data were checked, entered and analyzed using SPSS 15 for Windows. Data were expressed as mean \pm SD for quantitative variable, number and percentage for qualitative one. Chi-squared (X2) or fisher exact, $t$ test and paired $t$ test were used when appropriate. $\mathrm{P}<0.05$ was considered significant.

\section{RESULTS}

In our study, no significant differences were observed between both groups with respect to the following baseline characteristics: patient age and sex; Child Pugh class; proportions of patients positive for hepatitis $\mathrm{C}$ virus antibody and positive for hepatitis B surface antigen (Table 1).

The biochemical profile in our study (performed before and one month after the end of sessions) showed no statistically significant difference as regard all parameters in PAI and mitoxantron group, while in RFA group, $\alpha \mathrm{FP}$ and ALT show statistically significant improvement in those patients after the procedure $(\mathrm{P}=0.042$ and 0.001 respectively).

Concerning the complications encountered in our study as shown in table (2). The most frequent complication was intolerable pain (needs analgesics) which was significantly higher in group II $(45 \%)$ than in group I $(16.6 \%)$. Other complications; vomiting, fever and pleural effusion were comparable in both groups. All these complications were controlled by conservative management.

Regarding primary success (complete ablation): After one month, there was no statistically significant difference between both groups regarding procedure success (Table 3 ).

Regarding endpoint of our study: there was no statistically significant difference among patients of studied groups as regards stationary ablation (cancer free survival), local recurrence rate and overall survival. By the end point of the study; in group I; 7(11.67\%) patients died due to terminal hepatic failure as a result of multifocal hepatoma (4 patients), and hepatorenal syndrome after spontaneous bacterial peritonitis (3 patients). While 5 patients were discontinued due to develop of new focal lesion (4 patients) and develop of decompensation (1 patient). On the other hand, 
in group II; 5 (8.33\%) patients died due to terminal hepatic failure as a result of multifocal hepatoma (3 patients), and repeated attacks of bleeding (2 patients). While 5 patients were discontinued due to develop of new focal lesion (4 patients) and develop of decompensation (1 patient) (Table 4).
As regard to the lesion size, although the difference was statistically not significant but, Most of the ablated focal HCC lesions of both groups were less than $3 \mathrm{~cm}$ (Table 5).

Table (1) General features of the two groups:

\begin{tabular}{|c|c|c|c|c|c|c|c|}
\hline & \multicolumn{2}{|c|}{$\begin{array}{c}\text { Group I } \\
(n=60)\end{array}$} & \multicolumn{2}{|c|}{$\begin{array}{c}\text { Group II } \\
(n=60)\end{array}$} & \multicolumn{2}{|c|}{$\begin{array}{c}\text { Total } \\
(\mathbf{N}=\mathbf{1 2 0})\end{array}$} & $P$ value \\
\hline $\begin{array}{l}\text { Age } \\
\quad \text { Mean } \pm \text { SD }\end{array}$ & \multicolumn{2}{|c|}{$57.18 \pm 5.24$} & \multicolumn{2}{|c|}{$54.60 \pm 3.98$} & & & 0.071 \\
\hline Gender & No & $\%$ & No & $\%$ & No & $\%$ & \multirow[b]{2}{*}{0.782} \\
\hline $\begin{array}{c}\text { Male } \\
\text { Female }\end{array}$ & $\begin{array}{l}46 \\
14\end{array}$ & $\begin{array}{l}76.67 \\
23.33\end{array}$ & $\begin{array}{c}51 \\
9\end{array}$ & $\begin{array}{l}85 \\
15\end{array}$ & $\begin{array}{l}97 \\
23\end{array}$ & $\begin{array}{l}80.8 \\
19.2\end{array}$ & \\
\hline \multicolumn{8}{|l|}{ Viral markers } \\
\hline +ve HCV & 52 & 86.67 & 54 & 90 & 106 & 88.4 & \multirow{3}{*}{0.762} \\
\hline +ve HBV & 7 & 11.67 & 6 & 10 & 13 & 10.8 & \\
\hline $\mathrm{HCV} \& \mathrm{HBV}$ & 1 & 1.66 & 0 & 0.0 & 1 & 0.8 & \\
\hline \multicolumn{8}{|l|}{ Child-Pugh } \\
\hline Child A & 34 & 56.67 & 31 & 51.67 & 65 & 54.17 & \multirow{2}{*}{0.456} \\
\hline Child B & 26 & 43.33 & 29 & 48.33 & 55 & 45.83 & \\
\hline
\end{tabular}

Table (2): Complications related to both techniques among both studied groups.

\begin{tabular}{|c|c|c|c|c|c|c|c|}
\hline \multirow{2}{*}{ Complication } & \multicolumn{2}{|c|}{$\begin{array}{c}\text { Group I } \\
(\mathbf{n = 6 0})\end{array}$} & \multicolumn{2}{c|}{$\begin{array}{c}\text { Group II } \\
(\mathbf{n = 6 0})\end{array}$} & \multicolumn{2}{c|}{$\begin{array}{c}\text { Total } \\
\text { (N=120) }\end{array}$} & \multirow{2}{*}{ P value } \\
\cline { 2 - 7 } & $\mathbf{N o}$ & $\mathbf{\%}$ & $\mathbf{N o}$ & $\mathbf{\%}$ & $\mathbf{N o}$ & \% & \\
\hline Intolerable pain & 10 & 16.67 & 27 & 45.0 & 37 & 30.8 & 0.001 \\
\hline Vomiting & 4 & 6.67 & 7 & 11.67 & 11 & 9.2 & 0.526 \\
\hline Fever & 9 & 15.0 & 9 & 15.0 & 18 & 15.0 & 0.798 \\
\hline Pleural effusion & 2 & 3.33 & 3 & 5.0 & 5 & 4.2 & 1.000 \\
\hline Haematemesis & 0 & 0.0 & 1 & 1.67 & 1 & 0.8 & 1.000 \\
\hline Ascites (controllable) & 6 & 10.0 & 2 & 3.33 & 8 & 6.7 & 0.272 \\
\hline Decompensation (Child C) & 2 & 3.33 & 2 & 3.33 & 4 & 3.3 & 0.611 \\
\hline No complication & 27 & 45.0 & 9 & 15.0 & 36 & 30 & $<0.001$ \\
\hline P value & & & & 0.004 & & \\
\hline
\end{tabular}

Table (3): Follow up the success rate of both procedures after one month.

\begin{tabular}{|c|c|c|c|c|c|}
\hline \multirow{2}{*}{$\begin{array}{c}\text { According to } \\
\text { spiral CT }\end{array}$} & \multicolumn{2}{|c|}{$\begin{array}{c}\text { Group I } \\
(\mathbf{n = 6 0})\end{array}$} & \multicolumn{2}{|c|}{$\begin{array}{c}\text { Group II } \\
(\mathbf{n = 6 0})\end{array}$} & P \\
value
\end{tabular}


Table (4): End point of both studied groups after one year follow up.

\begin{tabular}{|c|c|c|c|c|c|}
\hline \multirow{2}{*}{} & \multicolumn{2}{|c|}{$\begin{array}{c}\text { Group I } \\
(\mathbf{n = 6 0})\end{array}$} & \multicolumn{2}{c|}{$\begin{array}{c}\text { Group II } \\
(\mathbf{n = 6 0})\end{array}$} & \multirow{2}{*}{ P } \\
& No & \%alue \\
\cline { 2 - 5 } & 44 & 73.33 & 49 & 81.66 & 0.381 \\
\hline $\begin{array}{c}\text { Stationary ablation } \\
\text { (cancer free survival) }\end{array}$ & 4 & 6.67 & 1 & 1.67 & 0.360 \\
\hline Local recurrence & 5 & 8.33 & 5 & 8.33 & 0.741 \\
\hline Discontinued cases & 7 & 11.67 & 5 & 8.33 & 0.760 \\
\hline Total deaths & 53 & 88.33 & 55 & 91.67 & 0.760 \\
\hline Overall survival & & & & & \\
\hline
\end{tabular}

Table (5): Outcome of the study in relation to HCC lesion diameter in both studied groups one year after treatment.

\begin{tabular}{|c|c|c|c|c|c|c|c|c|}
\hline & \multicolumn{4}{|c|}{ Group I } & \multicolumn{4}{|c|}{ Group II } \\
\hline & \multicolumn{2}{|c|}{$\begin{array}{c}\text { Size }<3 \mathrm{~cm} \\
(\mathrm{n}=27)\end{array}$} & \multicolumn{2}{|c|}{$\begin{array}{c}\text { Size } \geq 3 \mathrm{~cm} \\
(\mathrm{n}=33)\end{array}$} & \multicolumn{2}{|c|}{$\begin{array}{c}\text { Size }<3 \mathrm{~cm} \\
(\mathrm{n}=38)\end{array}$} & \multicolumn{2}{|c|}{$\begin{array}{c}\text { Size } \geq 3 \mathrm{~cm} \\
(\mathrm{n}=22)\end{array}$} \\
\hline & No & $\%$ & No & $\%$ & No & $\%$ & $\overline{\text { No }}$ & $\%$ \\
\hline $\begin{array}{l}\text { Stationary ablation } \\
\text { (cancer free period) }\end{array}$ & 22 & 81.5 & 22 & 66.67 & 33 & 86.84 & 16 & 72.72 \\
\hline Local recurrence & 1 & 3.7 & 3 & 9.09 & 1 & 2.63 & 0 & 0.0 \\
\hline Total deaths & 3 & 11.11 & 4 & 12.12 & 2 & 5.26 & 3 & 13.64 \\
\hline Overall survival & 24 & 88.89 & 29 & 87.87 & 36 & 94.73 & 19 & 86.3 \\
\hline$P$ value & \multicolumn{4}{|c|}{0.554} & \multicolumn{4}{|c|}{0.154} \\
\hline
\end{tabular}

\section{DISCUSSION}

Percutaneous Ablation is the best treatment option for patients with early stage HCC who are not suitable for surgical resection (SR) or transplantation [19].

The advantages of PAI are that it is easy to perform and have greater safety and tolerance than RFA. However, RFA has the advantage of requiring fewer treatment sessions and yielding a higher rate of complete tumour necrosis and local recurrence free survival at the risk of a higher rate of major complications [20,21].

Previous literature reporting the therapeutic efficacy of PAI is rather limited, and few studies have specifically compared the therapeutic efficacy between RFA and PAI for HCC [22].

Till the time this study is planned for in March 2012, few studies had been published to evaluate effect of percutaneous radiofrequency ablation and injection of acetic acid in treatment of HCC, but only one study evaluating percutanous injection of mitoxantrone in treatment of HCC was published by Farre et al. [15] and only two studies- to our knowledge-evaluated the effect of percutanous injection of combined ethanol and mitoxantrone in treatment of HCC $[\mathbf{2 3}, \mathbf{2 4}]$.

RFA is generally considered a relatively low risk procedure [25]. In this study, although the incidence of complications was significantly higher in the RFA group, no major complications apart from single case of haematemesis $(0.8 \%)$ and no RFTA related deaths occurred and most complications were minor and mainly transient.

This was not in agreement with Curley et al. [26], Poon et al. [27] and Huo et al. [28] who rate major complications of $13.1 \%, 17 \%$ and $9.2 \%$ respectively. The difference in major complication is attributed to selection of patients and experience of the operator. The occurrence of major complication as haemothorax and haemoperitoneum in subcapsular tumors where injury of the pleura and capsule of the liver is due to a technical error and bad selection of subcapsular lesions.

Here, we must point out that some of the complications observed could be due to the effect of the learning curve [27], and professionals' differing degree of experience in RFA [29]. 
PAI causes ablation of HCC in $89 \%$ of cases selected by Ohnishi et al. [16]. PAI followed by local injection of mitoxantrone resulted in $85 \%$ ablation rate in our study. On the other hand ElKady et al. [30] ablated 75\% of HCC cases using acetic acid injection [30]. The difference in these results may be attributed to patient's selection criteria and tumor size in each study.

The complete ablation rate of combined PAI plus mitoxantrone was comparable with RFA results $85 \%$ versus $88.3 \%$ respectively with no statistically significant difference between both groups in our study. However El-Kady et al. [30] found statistically significant difference between PAI and RFA in his study. This difference between both studies could be attributed to the size of the lesion or to the additive DNA damaging effect of mitoxantrone on $\mathrm{HCC}$ after completion of PAI. The initial injection of acetic acid leads to blockage of the blood vessels of the tumors which in turn leads to persistence of mitoxantron in the tumor in high concentration and prevent its systemic effect.

Ohishi and his colleagues [31] stated that Intratumoral instillation of mitoxantrone results in a 1000-fold higher concentration in the tumor compared with intravenous administration, moreover ; lipidol have high affinity to malignant hepatocyts so it increase the duration and efficacy of mitoxantrone. After that Farre et al. [15] selected mitoxantrone for local treatment of malignant liver lesions because of its low tissue toxicity, high intratumoral concentration after intratumoral instillation, and long time in the tumor, since it has a tendency to remain at the application site [14]. The histological effects of locoregional mitoxantrone treatment were evaluated by Hoffmann et al. [32] and characterized by complete tumor necrosis in which dead tumor cells are surrounded by an inflammatory infiltrate and a fibrotic organization of liver tissue around the tumor.

Also we can't neglect the effect of acetic acid on the tumor tissue as it has a strong ability to penetrate cells and can dissolve lipids and extract collagen from intra-tumoral septa and capsules that frequently contain viable cancer cells [11], leading to more localization and hence more effect of mitoxantrone on malignant tissue.

Our results also showed that overall survival was not significantly different but higher in the RFTA group (91.67\%) than in the PAI and mitoxantrone group $(88.33 \%)$. This finding was in agreement with that of Lin et al. [22] in which the one year survival was $93 \%$ and $90 \%$ in RFA group and PAI group respectively. The cause of death was HCC progression in most cases. Therefore, a more effective local treatment such as RFA can achieve lower HCC recurrence and consequently contributes to better survival.

Our results were close to the study done by Guglielmi et al. [33]. They had found the survival rate of patients after treatment were $87 \%$ after 1 year. Survival was significantly related to Child Pugh class After 3 years survival was $83 \%$ in Child Pugh A cirrhotic patients and $31 \%$ in Child Pugh B patients.

Cancer free survival reflects local recurrence and new tumour formation elsewhere in the liver. Because lower recurrence was lower in the RFA group therefore the cancer free survival rate was also higher in RFTA group than in the other group in this study.

The local recurrence rate was higher in patients with HCCs larger than $3 \mathrm{~cm}$. The independent factors related to local recurrence were large tumour size $(>3 \mathrm{~cm})$. This result was consistent with that of Komorizono and colleagues [34]. A larger tumour usually has a higher rate of local recurrence because it frequently requires multiple overlapping ablations, and targeting of its viable foci is difficult because of lack of clarity of the image obtained between the ablated and non-ablated tumour after repeated ablation is performed under sonography [35].

Despite the wider range (1 cm safety margin) of injections of acetic acid herein, the distribution of acetic acid might be unpredictable both within the tumour and outside due to interference of the fibrous septum [10] and the presence of satellite nodules around the target tumour [36] respectively.

Therefore, a $1 \mathrm{~cm}$ safety margin can be achieved in patients treated with RFA but not in patients treated with PEI or PAI. This limitation of the homogenous distribution of ethanol or acetic acid around the safety margin of the target tumour may explain the benefit of lower local recurrence favouring RFA than PEI or PAI in treating HCCs larger than $3 \mathrm{~cm}$ in the present study or in other investigations $[\mathbf{1 0 , 3 4 , 2 2}]$. The rates of new $\mathrm{HCC}$ recurrence were also similar among the two groups, perhaps because of the similar baseline parameters. 
PAI required fewer treatment sessions and smaller volume of injection materials to achieve complete tumour necrosis than PEI and provided better survival after long-term follow-up [37]. An additional advantage of PAI therapy over PEI is its ability to destroy more effectively, in small time and not limited by a formation. In contrast, fewer injection sessions are required in PAI, because acetic acid injected into one nodule will penetrate through septa largely because of its low $\mathrm{pH}$, which induces swelling of the fibers and promotes dissociation of intermolecular cross-links containing aldimine bonds of collagen in the septa $[\mathbf{3 8 , 3 9 , 1 0 ]}$.

Despite of all this advantages of PAI over PEI, yet mitoxantrone fill this gap as concluded by a study done by Helmy et al [24] in which the cancer free survival after one year was $71.9 \%$ in consistent with our results in which the cancer free survival after one year was $73.33 \%$.

From this study and its results, we can observe that PAI and mitoxantrone is a very effective method for ablating HCC, with high power to penetrate the septa and the capsule. It is simple and applicable technique, this is particularly important in emerging economies where $\mathrm{HCC}$ is prevalent. Compared to RFA; acetic acid is cheap, readily available, besides being equally effective and safe. All these criteria enables acetic acid to be the first choice ablative procedure especially in low economic levels where facilities are minimum or lacking or when the lesions are not candidate for RFA.

\section{CONCLUSION}

PAI followed by mitoxantrone seems to be comparable to radiofrequency ablation in the treatment of HCC.

Funding: None.

Conflicts of interest: None.

Ethical approval: A written informed consent was taken from all included patients, and the ethical committee of the university has accepted the study under the number of 213/12-5-2012.

\section{REFERENCES}

1. El-Serag HB. Epidemiology of viral hepatitis and hepatocellular carcinoma. Gastroenterology 2012, 142: 1264-1273.

2. Bosch FX, Ribes J, Diaz M, Cleries R. Primary liver cancer: worldwide incidence and trends. Gastroenterology 2004, 127: S5S16.
3. Llovet JM, Fuster J, Bruix J. The Barcelona approach: diagnosis, staging, and treatment of hepatocellular carcinoma. Liver Transpl 2004,10: S115-120.

4. Llovet JM, Bruix J. Novel advancements in the management of hepatocellular carcinoma in 2008. J Hepatol 2008, 48: S20-S37.

5. Llovet JM, Bustamante J, Castells A, Vilana R, Ayuso Mdel C, Sala M, et al. Natural history of untreated nonsurgical hepatocellular carcinoma: rationale for the design and evaluation of therapeutic trials. Hepatology 1999, 29: 62-67.

6. Llovet JM, Burroughs A, Bruix J. Hepatocellular carcinoma. Lancet 2003, 362: 1907-1917.

7. Germani G, Pleguezuelo M, Gurusamy K, Meyer T, Isgro G, Burroughs AK. Clinical outcomes of radiofrequency ablation, percutaneous alcohol and acetic acid injection for hepatocellular carcinoma: a meta-analysis. J Hepatol 2010, 52: 380-388.

8. Raza A, Sood GK. Hepatocellular carcinoma review: Current treatment, and evidencebased medicine. World $J$ Gastroenterol 2014, 20(15): 4115-4127.

9. Kudo, M. Radiofrequency ablation for hepatocellular carcinoma: updated review in 2010. Oncology 2010, 78 (Suppl 1): 113124.

10. Ohnishi K, Yoshioka H, Ito S, Fujiwara K. Prospective randomized controlled trial comparing percutaneous acetic acid injection and per-cutaneous ethanol injection for small hepato-cellular carcinoma. Hepatology 1998, 27: 67-72.

11. Huo TI, Huang YS, Wu JC. Percutaneous ablation therapy for hepatocellular carcinoma: current practice and future perspectives. J Chin Med Assoc 2005, 68: 155-159.

12. Zamboglou N, Wurm R, Pape H. Simultaneous radiotherapy and intratumoral instillation of mitoxantrone in locoregional recurrence of head and neck carcinoma. Reg Cancer Treat 1991, 4: 79-84.

13. Fox ME, Smith PJ. Subcellular localisation of the antitumour drug mitoxantrone and the induction of DNA damage in resistant and sensitive human colon carcinoma cells. Cancer Chemother Pharmacol 1995, 35: 403-410.

14. 14-Markman M, Alberts D, Rubin S, Hakes T, Lewis JL, Reichma B, et al. Evidence for persistence of mitoxantrone within the peritoneal cavity following intraperitoneal delivery. Gynecol Oncol 1993, 48: 185-188. 
15. Farres MT, de Baere T, Lagrange C, Ramirez L, Rougier R, Munck JN, et al . Percutaneous Mito-xantrone Injection for Primary and Seconrary Liver Tumors. Cardiovascular and Interventional Radiology 1998, 21(5): 399-403.

16. Ohnishi K, Yoshioka H, Ito S, Fujiwara K. Treatment of nodular hepatocellular carcinoma larger than $3 \mathrm{~cm}$ with ultrasoundguided per-cutaneous acetic acid injection. Hepatology 1996, 24(6): 1379-1385.

17. Tanaka S, Shimada M, Shirabe K, Taketomi A, Maehara S, Tsujita E, et al. Surgical radio-frequency ablation for treatment of hepatocellular carcinoma: an endoscopic or open approach. Hepatogastroenterology 2009, 56(93):1169-1173.

18. Chen MH, Yang W, Yan K, Zou MW, Solbiati L, Liu JB, et al. Large Liver Tumors: Protocol for Radiofrequency Ablation and Its Clinical Application in 110 Patients - Mathematic Model, Overlapping Mode, and Electrode Placement Process. Radiology 2004, 232(1): 260-271.

19. Bruix J, Sherman M. AASLD practice guidlines: Management of Hepatocellular Carcinoma. Hepatology 2005, 42(5): 12081236.

20. Livraghi T, Goldberg SN, Lazzaroni S, Meloni F, Solbiati L, Gazelle GS. Small hepatocellular carcinoma: treatment with radio-frequency ablation versus ethanol injection. Radiology 1999, 210(3): 655-661.

21. Lencioni RA, Aligaier HP, Cioni D, Olschewski M, Deibert P, Crocetti L, et al. Small hepatocellular carcinoma in cirrhosis: randomized comparison of radiofrequency thermal ablation versus percutaenous ethanol injection. Radiology 2003, 228(1): 235-240.

22. Lin SM, Lin CJ, Lin CC, Hsu CW, Chen YC. Randomised controlled trial comparing percutaneous radiofrequency thermal ablation, per-cutaneous ethanol injection, and percutaneous acetic acid injection to treat hepatocellular carcinoma of $3 \mathrm{~cm}$ or less. Gut 2005, 54(8): 1151-1156.

23. Bihery AS, El-Shamy MH, El-Mokadem TE, Zaher TI, Abd El Dayem WA, Fathy T, et al. Percutaneous Local Injection of Ethanol and Mitoxantrone in Treatment of Hepatocellular Carcinoma. Afro-Egypt $J$ Infect Endem Dis 2011, 1 (2): 28-36.

24. Helmy BM. Percutaneous Local Injection of Ethanol and Mitoxantrone versus radiofrequency ablation in the Treatment of Hepatocellular Carcinoma. MD Thesis. Tropical Medicine Department, Faculty of Medicine, Zagazig University, Egypt. 2015, P.: 129-43.
25. Livraghi T, Solbiati L, Meloni MF, Gazelle GS, Halpern EF, Goldberg SN. Treatment of focal liver tumors with percutaneous radiofrequency ablation: complications encountered in a multicenter study. Radiology 2003, 226(2): 441-451.

26. Curley SA, Izzo F, Ellis LM, Nicolas Vauthey J, Vallone P. Radiofrequency ablation of hepatocellular cancer in 110 patients with cirrhosis. Ann Surg. 2000, 232(3): 381-391.

27. Poon RT, Ng KK, Lam CM, Ai V, Yuen J, Fan ST. Effectiveness of radiofrequency ablation for hepatocellular carcinomas larger than $3 \mathrm{~cm}$ in diameter. Arch Surg. 2004,139(3): 281-287.

28. Huo TI, Huang YH, Huang HC, Wu JC, Lee PC, Chang FY, et al. Fever and Infectious Complications After Percutaneous Acetic Acid Injection Therapy for Hepatocellular Carcinoma: Incidence and Risk Factor Analysis. J Clin Gastroenterol 2006, 40(7): 639-642.

29. Hildebrand P, Leibecke T, Kleemann M, Mirow L, Birth M, Brusch HP, et al. Influence of operator experience in radiofrequency ablation of malignant liver tumours on treatment outcome. Eur J Surg Oncol 2006, 32(4): 430-434.

30. El-Kady N, El-Bendary M, El-Sherbeeny W, El-Diasty M. Medium and large sized hepatocellular carcinoma: acetic acid versus radiofrequency ablation. MMJ 2011, 24(1): 21-30.

31. Ohishi H, Uchida H, Yoshimura H, Ohue S, Ueda J, Katsuragi M, et al. Hepatocellular carcinoma detected by iodized oil: Use of anticancer agents. Radiology 1985, 154(1): 25-29.

32. Hoffmann W, Reichel H, Schiebe M, Btiltmann B, Bamberg M. Intrapericardial instillation of mitoxantrone in malignant pericarditis: Histo-pathological appearance. Reg Cancer Treat 1993, 2: 91-99.

33. Guglielmi A, Ruzzenente A, Battocchia A, Tonon A, Fracastoro G, Cordiano C. Radiofrequency ablation of hepatocellular carcinoma in cirrhotic patients. Hepatogastroenterology 2003, 50(50): 480484.

34. Komorizono Y, Oketani M, Sako K, Yamasaki N, Shibatou T, Maeda M, et al. Risk factors for local recurrence of small hepatocellular carcinoma tumors after a single session, single application of percutaneous radiofrequency ablation. Cancer 2003, 97(5): 1253-1262. 
35. Cha CH, Lee FT Jr, Gurney JM, Markhardt BK, Warner TF, Kelcz F, et al. CT versus sonography for monitoring radiofrequency ablation in a porcine liver. Am J Roentgenol 2000, 175(3): 705-711.

36. Okusaka $\mathrm{T}$, Okada $\mathrm{S}$, Ueno $\mathrm{H}$, Ikeda M, Shimada K, Yamamoto J, et al. Satellite lesions in patients with small hepatocellular carcinoma with reference to clinicopathologic features. Cancer 2002, 95 (9):1931-1937.

37. Tsai WL, Cheng JS, Lai KH, Lin CP, Lo GH, Hsu PI, et al. Clinical trial: percutaneous acetic acid injection vs. percutaneous ethanol injection for small hepatocellular carcinomaa long- term follow-up study. Aliment Pharmacol Ther 2008, 28(3): 304-311.
38. Timpl R, Wiedemann H, Delden VV, Furthmayr $\mathrm{H}$, Kuhn K. A network model for the organization of type IV collagen molecules in basement membranes. Eur J Biochem 1981, 120(2): 203-211.

39. Miller E, Rhodes RK. Preparation and characterization of the different types of collagen. In: Cunningham LW, Frederiksen DW, eds. Methods in enzymology. Volume 82. Structural and contractile proteins. Part A. Extracellular matrix. New York: Academic, 1982:23-64.

Peer reviewer: Tarik Zaher ,Professor of Tropical Medicine and Hepatogastroenterology, Faculty of Medicine, Zagazig University, Egypt.

Editor: Mohamed Emara, Lecturer of Tropical Medicine and Hepatogastroenterology, Faculty of Medicine, Zagazig University, Egypt 